Article

\title{
Two-Step Spark Plasma Sintering Process of Ultrafine Grained WC-12Co-0.2VC Cemented Carbide
}

\author{
Zhenhua Wang *, Jiheng Jia, Boxiang Wang and Yulin Wang * \\ School of Mechanical Engineering, Nanjing University of Science and Technology, Nanjing 210094, China \\ * Correspondence: wzh1980@njust.edu.cn (Z.W.); wyl_sjtu@njust.edu.cn (Y.W.)
}

Received: 16 July 2019; Accepted: 30 July 2019; Published: 31 July 2019

\begin{abstract}
Ultrafine grained WC-12Co-0.2VC (named UYG12V) cemented carbides were prepared via the two-step spark plasma sintering (SPS) in this study. First, the effects of the sintering temperature on the relative density and WC grain size of UYG12V cemented carbides were studied. The results show that regular WC grains form when sintered at $1300^{\circ} \mathrm{C}$. The sintered body begins to rapidly densify and WC grains grow slowly when sintered at $1200{ }^{\circ} \mathrm{C}$. Thus, the first-step (T1) and the second-step (T2) temperatures in the two-step SPS of UYG12V are $1300^{\circ} \mathrm{C}$ and $1200{ }^{\circ} \mathrm{C}$, respectively. The effect of the holding time during the first and second steps on the mechanical properties was also studied. The results show that the UYG12V cemented carbide sintered at $1300^{\circ} \mathrm{C}$ for $3 \mathrm{~min}$ and then at $1200^{\circ} \mathrm{C}$ for $5 \mathrm{~min}$ has the best comprehensive mechanical properties, exhibiting the average particle size, Vickers hardness, fracture toughness, relative density, and bending strength of $271 \mathrm{~nm}$, 18.06 GPa, 12.25 $\mathrm{MPa} \mathrm{m}^{1 / 2}, 99.49 \%$, and $1960 \mathrm{MPa}$, respectively.
\end{abstract}

Keywords: spark plasma sintering; two-step; ultrafine grain; cemented carbide; relative density

\section{Introduction}

Due to its high hardness, high wear resistance, stability at high temperature, and other mechanical properties, cemented carbide is widely used in cutting, drilling, and some mining equipment and components [1]. The hardness and strength of cemented carbides improve as the WC grain size decreases to nanometer levels. Therefore, the ultrafine grained cemented carbide has better mechanical properties compared with ordinary alloys. However, during preparation of the ultrafine grained cemented carbide, crystal grains are more likely to grow during sintering because nano-WC particles have a lower surface energy than ordinary WC particles [2-4], and it is difficult to obtain ultrafine WC grains using conventional sintering. At present, these are two main ways to inhibit WC grain growth: Adding grain growth inhibitors and selecting a rapid sintering process $[5,6]$.

Most grain growth inhibitors reported in the literature are transition metal carbides, such as $\mathrm{TiC}$, $\mathrm{VC}, \mathrm{Cr}_{3} \mathrm{C}_{2}, \mathrm{ZrC}, \mathrm{NbC}, \mathrm{TaC}$, and $\mathrm{HfC}$ [7]. Among the inhibitors reported in the literature, $\mathrm{VC}$ has the best inhibitory performance, followed by $\mathrm{Cr}_{3} \mathrm{C}_{2}$ [8]. Song et al. [9] prepared the WC-10 ultrafine grained cemented carbide with less than $120 \mathrm{~nm}$ particle size and $98.5 \%$ relative density with VC as an inhibitor by spark plasma sintering (SPS) at $1100{ }^{\circ} \mathrm{C}$ for $5 \mathrm{~min}$. The hardness and fracture toughness of the cemented carbide are $H_{\mathrm{V}}=2050 \pm 10 \mathrm{kgf} \mathrm{mm}^{-2}$ and $K_{\mathrm{IC}}=14.5 \pm 0.5 \mathrm{MPa} \mathrm{m}^{1 / 2}$, respectively. However, the inhibitor preferentially dissolves and continuously precipitates in the Co phase, which changes the wettability and fluidity of the Co phase and the solubility of WC in liquid $\mathrm{Co}$, affecting the density of the sintered body $[10,11]$.

In addition to adding inhibitors, a rapid sintering method and tuning the sintering process can suppress grain growth because the grain size grows as the temperature or holding time increase [12]. Joule heating is produced when a high pulse current passes through the sintered powder, providing a sintering effect during SPS [13]. Compared with other sintering methods, SPS provides rapid heating 
and can complete sintering in a short time. Therefore, grain growth can be suppressed by reducing the grain growth time.

There have been many studies regarding the one-step SPS. Liu [14], Guo [15] and Yan [16] produced cemented carbide blocks with 2000 Vickers hardness and approximately $11 \mathrm{MPa} \mathrm{m} \mathrm{m}^{1 / 2}$ fracture toughness. However, rapid crystal grain growth is inevitable during the one-step SPS, where sintering is held for a certain period of time at a specific temperature. In order to restrain the crystal grain growth, one can lower the sintering temperature or shorten the holding time. However, if the sintering temperature is too low or the holding time is too short, the relative density of the sintered sample will decrease [17-20].

The two aforementioned methods reduce the relative density while suppressing the grain growth, thus the two-step sintering method emerged as the times required. Two-step sintering refers to a process wherein the ceramic is heated to a certain critical density after being heated to a high temperature, and the body is rapidly cooled to a second temperature and held for a long period of time. This process yields ultrafine grained ceramics with high relative density [21]. Yin et al. [22] improved the mechanical properties of ceramics using the two-step SPS compared with the ordinary one-step sintering. In the study of Zheng et al., the fracture toughness of WC-Si ${ }_{3} \mathrm{~N}_{4}$ increased from 9.46 MPa $\mathrm{m}^{1 / 2}$ to $10.94 \mathrm{MPa} \mathrm{m}^{1 / 2}$ using the two-step SPS [23]. Although many studies have focused on the two-step sintering of ceramic cutting tools, research on the two-step sintering of tungsten-cobalt cemented carbides is rare.

Many research results show that WC grains grow as the sintering temperature and holding time increase. The formation of WC grains with regular morphology requires a high sintering temperature, and densification requires a long holding time during sintering of the cemented carbide. Therefore, it is difficult to obtain ultrafine grains and high relative density materials simultaneously with a traditional one-step sintering. During the SPS of the cemented carbide, the temperature required to form WC grains with regular morphology is different than that required for densification. The former requires a higher temperature, while the latter requires a lower temperature corresponding to the slower growth of WC grains. Therefore, a two-step SPS sintering method for the UYG12V cemented carbide is proposed in this paper. First, a higher sintering temperature (first-step temperature $\mathrm{T}_{1}$ ) and shorter holding time (first-step holding time $t_{1}$ ) are used to rapidly form regular fine WC grains. The sintering temperature is subsequently reduced (second-step temperature $\mathrm{T}_{2}$ ) and held for a longer time (second-step holding time $t_{2}$ ), allowing the materials to densify further.

In this study, the effect of the temperature on the relative density and grain size during the one-step sintering was first studied in order to determine $T_{1}$ and $T_{2}$. The effects of various $t_{1}$ and $t_{2}$ values on the relative density, microstructure, and mechanical properties of UYG12V cemented carbides were studied, and the optimal values of $t_{1}$ and $t_{2}$ were determined.

\section{Materials and Methods}

The cemented carbide examined herein is composed of $87.8 \mathrm{wt} \%$ WC powder $(99.9 \%$ purity, $60 \mathrm{~nm}), 12 \mathrm{wt} \%$ Co powder (99.9\% purity, $600 \mathrm{~nm})$, and $0.2 \mathrm{wt} \%$ VC powder $(99.9 \%$ purity, $600 \mathrm{~nm})$ produced by Shanghai Chaowei Nanotechnology (Shanghai, China). After weighing, the mixed powder was poured into a conical bottle with absolute ethyl alcohol as a vibration medium for ultrasonic vibration while stirring. After $2 \mathrm{~h}$ of ultrasonic vibration, the mixed slurry was placed in a vacuum drying chamber and dried at $115^{\circ} \mathrm{C}$. The powder was ground and sifted with a 100 mesh screen after drying. Finally, the prepared powder was placed in a sealed bag for reserve.

An appropriate amount of mixed powder was weighed in the graphite mold with $15 \mathrm{~mm}$ diameter bore, and the mold was brought to $10 \mathrm{MPa}$ pre-pressure and held for $3 \mathrm{~min}$. The prepressed mold was placed in a sintering furnace (LABOX ${ }^{\mathrm{TM}}-650 \mathrm{~F}$, Sinter Land INC., Nagaoka, Japan) to be sintered at a $30 \mathrm{MPa}$ load. Finally, the sintered samples were allowed to cool to room temperature.

The sintered samples were polished and their mechanical properties were tested. The scanning electron microscopy (SEM, Quant250FEG, FEI, Hillsboro, OR, USA) was used to examine the 
microstructure of the material. One hundred grains were randomly measured by the Image-Pro 6.0 software. Density was measured using the Archimedes drainage method. The bending strength was measured using an electronic universal testing machine (UTM5105-G, Hengsisheng, Jinan, China). The Vickers hardness on the polished surface was measured using a Vickers diamond pyramid indenter (MN-9631-130-C, INSIZE, Tianjin, China) with $294 \mathrm{~N}$ load and $15 \mathrm{~s}$ loading holding time. The fracture toughness $\left(\mathrm{K}_{\mathrm{IC}}\right)$ was calculated from the length of cracks generated at the four corners of the indenter during loading:

$$
\mathrm{K}_{\mathrm{IC}}=0.15 \sqrt{\frac{H V_{30}}{\sum \mathrm{L}}},
$$

where $\mathrm{L}$ is the length of the crack in the formula.

There are two samples at each sintering temperature. The relative density and bending strength were measured three times and hardness and fracture toughness were measured five times on each sample. First, a one-step sintering experiment was conducted in order to explore the effect of the temperature on the relative density and grain size. The sintering temperature was 1150, 1200, 1250, 1300 , and $1350{ }^{\circ} \mathrm{C}$ with $100{ }^{\circ} \mathrm{C} / \mathrm{min}$ heating rate and $1 \mathrm{~min}$ holding time. Once $\mathrm{T}_{1}$ and $\mathrm{T}_{2}$ were determined, the two-step SPS experiments with the UYG12V cemented carbide were conducted at different $t_{1}$ and $t_{2}$ values. The heating rate from 0 to $T_{1}$ was $100{ }^{\circ} \mathrm{C} / \mathrm{min}$, and the cooling rate from $\mathrm{T}_{1}$ to $\mathrm{T}_{2}$ was $200^{\circ} \mathrm{C} / \mathrm{min}$ during the two-step sintering experiments. The number of samples, experimental design, and results are shown in Table 1.

Table 1. Number of samples, experimental design, and results.

\begin{tabular}{|c|c|c|c|c|c|c|c|}
\hline $\begin{array}{l}\text { Number of } \\
\text { Samples }\end{array}$ & $\begin{array}{c}\mathbf{t}_{1} \\
(\mathrm{~min})\end{array}$ & $\begin{array}{c}t_{2} \\
\text { (min) }\end{array}$ & $\begin{array}{c}\text { Relative } \\
\text { Density } \\
(\%)\end{array}$ & $\begin{array}{l}\text { Grain Size } \\
\quad(\mathrm{nm})\end{array}$ & $\begin{array}{c}\text { Hardness } \\
\text { (GPa) }\end{array}$ & $\begin{array}{c}\text { Fracture } \\
\text { Toughness } \\
\left(\mathrm{MPa} \mathrm{m}^{1 / 2}\right)\end{array}$ & $\begin{array}{c}\text { Bending } \\
\text { Strength } \\
\text { (MPa) }\end{array}$ \\
\hline $1 \mathrm{a}$ & 1 & 3 & 98.34 & 237.9 & 17.34 & 13.53 & 1504 \\
\hline $1 b$ & 1 & 5 & 98.35 & 240.4 & 17.35 & 12.81 & 1542 \\
\hline $1 c$ & 1 & 7 & 98.92 & 252.3 & 17.16 & 12.23 & 1596 \\
\hline $1 d$ & 1 & 10 & 98.98 & 254.5 & 17.43 & 12.88 & 1642 \\
\hline $2 a$ & 2 & 3 & 98.79 & 259.4 & 17.64 & 12.67 & 1576 \\
\hline $2 b$ & 2 & 5 & 99.35 & 269.6 & 17.87 & 12.98 & 1672 \\
\hline $2 c$ & 2 & 7 & 99.35 & 269.8 & 17.77 & 13.21 & 1796 \\
\hline $2 d$ & 2 & 10 & 99.52 & 279.5 & 17.68 & 13.47 & 1601 \\
\hline $3 a$ & 3 & 3 & 98.82 & 255.3 & 17.49 & 12.24 & 1647 \\
\hline $3 b$ & 3 & 5 & 99.49 & 271.0 & 18.06 & 12.25 & 1960 \\
\hline $3 c$ & 3 & 7 & 99.41 & 275.7 & 17.57 & 12.45 & 1848 \\
\hline $3 d$ & 3 & 10 & 99.42 & 286.5 & 17.65 & 12.87 & 1706 \\
\hline $4 a$ & 4 & 3 & 99.71 & 266.4 & 17.69 & 11.84 & 1818 \\
\hline $4 b$ & 4 & 5 & 99.53 & 283.3 & 17.44 & 12.55 & 1769 \\
\hline $4 c$ & 4 & 7 & 99.76 & 280.5 & 17.62 & 11.96 & 1689 \\
\hline $4 d$ & 4 & 10 & 99.96 & 300.8 & 17.65 & 12.30 & 1658 \\
\hline
\end{tabular}

\section{Results and Discussion}

\subsection{Analysis of Relative Density and Microstructure of UYG12V Cemented Carbide at Different Sintering Temperatures}

The relative density of the UYG12V cemented carbide sintered at different temperatures is shown in Figure 1. One can see in Figure 1 that the relative density of the samples is very low when sintered below $1150{ }^{\circ} \mathrm{C}$, and the relative density increases rapidly from $1150{ }^{\circ} \mathrm{C}$ to $1200{ }^{\circ} \mathrm{C}$. The relative density of the sample reaches near $99 \%$ when sintered at $1300{ }^{\circ} \mathrm{C}$. 


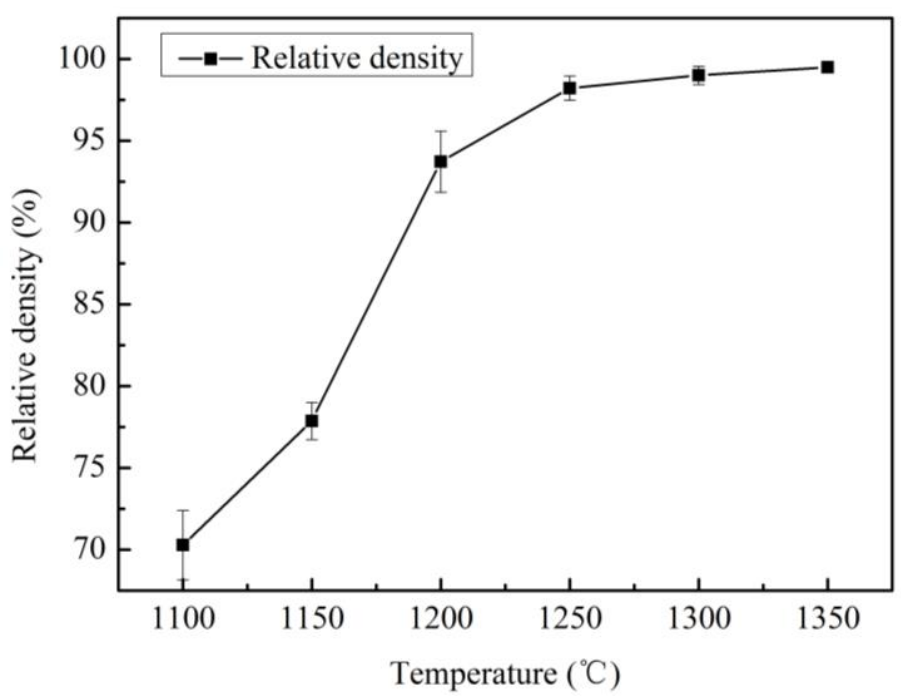

Figure 1. Relationship between relative density and sintering temperature.

The fracture morphology (non-corrosive) of the samples sintered at $1150{ }^{\circ} \mathrm{C}$ and $1200{ }^{\circ} \mathrm{C}$ is shown in Figure 2. Figure 2a shows that there are many gaps in the sample that are sintered at $1150{ }^{\circ} \mathrm{C}$, which reduces the relative density. Some WC grains with granular morphology are bonded to Co. Co liquifies during sintering at $1150^{\circ} \mathrm{C}$ and $1200^{\circ} \mathrm{C}$, and WC began dissolving in $\mathrm{Co}$, which marks the beginning of liquid state sintering. The capillary force formed by the liquid phase in the interstitial pore and viscous flow of the liquid phase itself changes the position of the particles and redistributes them to produce the tightest distribution, thus the relative density of the sintered body increases rapidly.
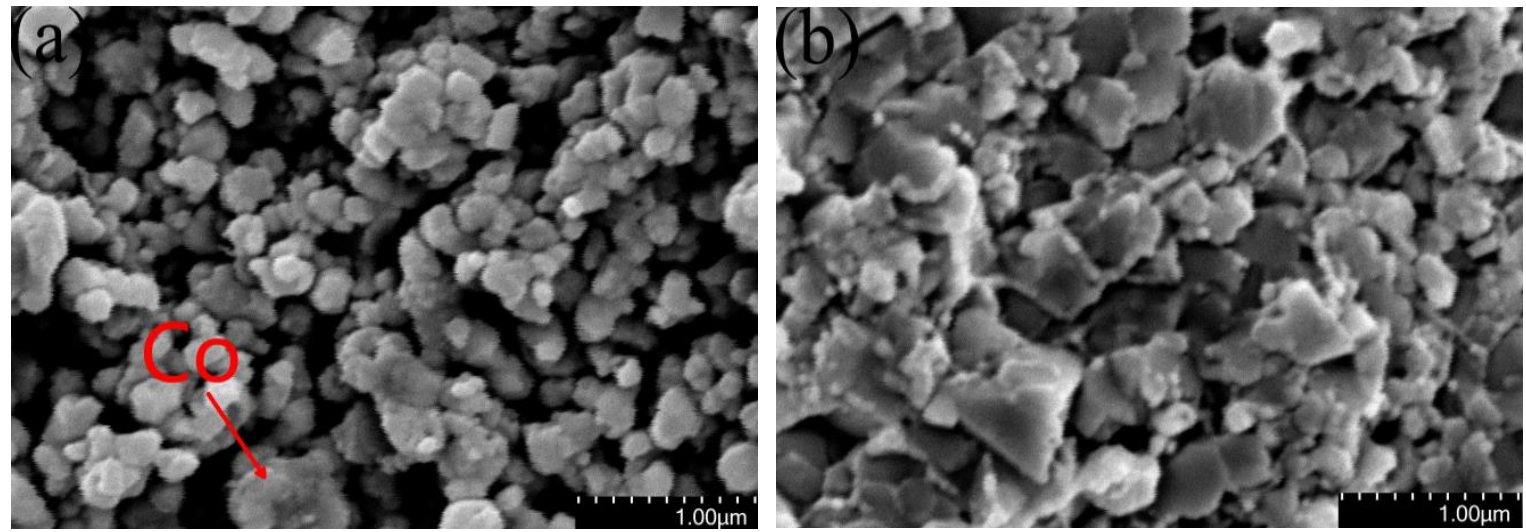

Figure 2. Fracture morphology of the samples sintered at (a) $1150{ }^{\circ} \mathrm{C}$ and (b) $1200{ }^{\circ} \mathrm{C}$.

Figure 2a WC particles still retain spherical powder shape at $1150^{\circ} \mathrm{C}$ due to the solid phase sintering. When the sintering temperature is $1200^{\circ} \mathrm{C}$, the liquid state sintering begins, but dissolution-precipitation of WC in Co is insufficient, and WC grains grow slowly. The relationship between the WC grain size and sintering temperature is shown in Figure 3, wherein one can see that WC grain sizes increase as the sintering temperature increases. This means that grains also grow faster when the sintering temperature exceeds $1250^{\circ} \mathrm{C}$. Most WC grains are irregular blocks that are not conducive to densification, and only a few WC grains reach equilibrium (triangular prism morphology), as shown in Figure 4a. The grain shape does not change much due to sintering at $1250^{\circ} \mathrm{C}$ compared with $1200^{\circ} \mathrm{C}$, as shown in Figure $4 \mathrm{~b}$. The number of WC grains with regular triangular prism increases significantly at $1300^{\circ} \mathrm{C}$, as shown in Figure 4c. Small, irregular WC grains are present in the samples sintered at $1200{ }^{\circ} \mathrm{C}$ and $1300{ }^{\circ} \mathrm{C}$, and the number of irregular WC grains decreases as the temperature increases. Rapid grain growth occurs during sintering at temperatures between $1300{ }^{\circ} \mathrm{C}$ and $1350{ }^{\circ} \mathrm{C}$, and the average grain size 
of WC rapidly increases from $208.8 \mathrm{~nm}$ to $246.8 \mathrm{~nm}$ as temperature increases, as shown in Figure 3. This occurs because the energy barrier preventing $W$ and $C$ migration increases as the temperature decreases [24]; migration of $\mathrm{W}$ and $\mathrm{C}$ and dissolution-precipitation of WC in Co proceed at a higher rate at high temperature, which promotes rapid grain growth. At $1350{ }^{\circ} \mathrm{C}$, most WC grains transform into triangular prisms, and nearly all WC particles less than $100 \mathrm{~nm}$ disappear, as shown in Figure $4 \mathrm{~d}$. Therefore, during the two-step sintering process, $\mathrm{T}_{1}=1300^{\circ} \mathrm{C}$ was chosen as the first-step temperature in order to form a regular grain morphology. $\mathrm{T}_{2}=1200^{\circ} \mathrm{C}$ was chosen as the second-step temperature in order to form the liquid phase, thus increasing the relative density of the samples while inhibiting rapid grain growth.

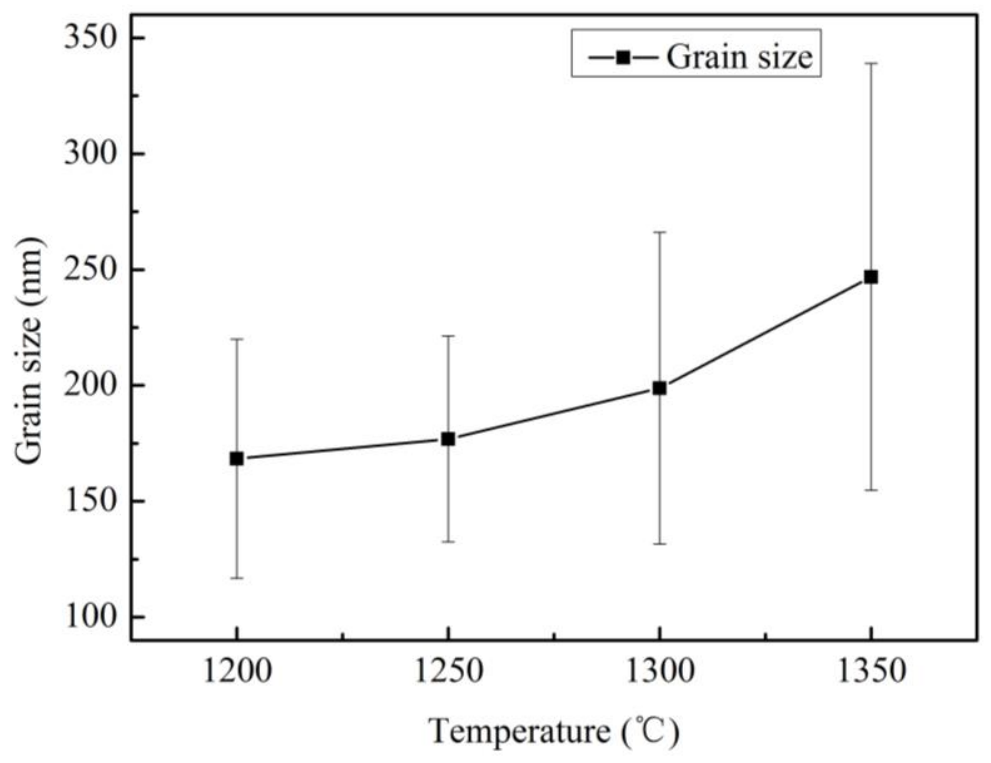

Figure 3. Relation between WC grain size and sintering temperature.
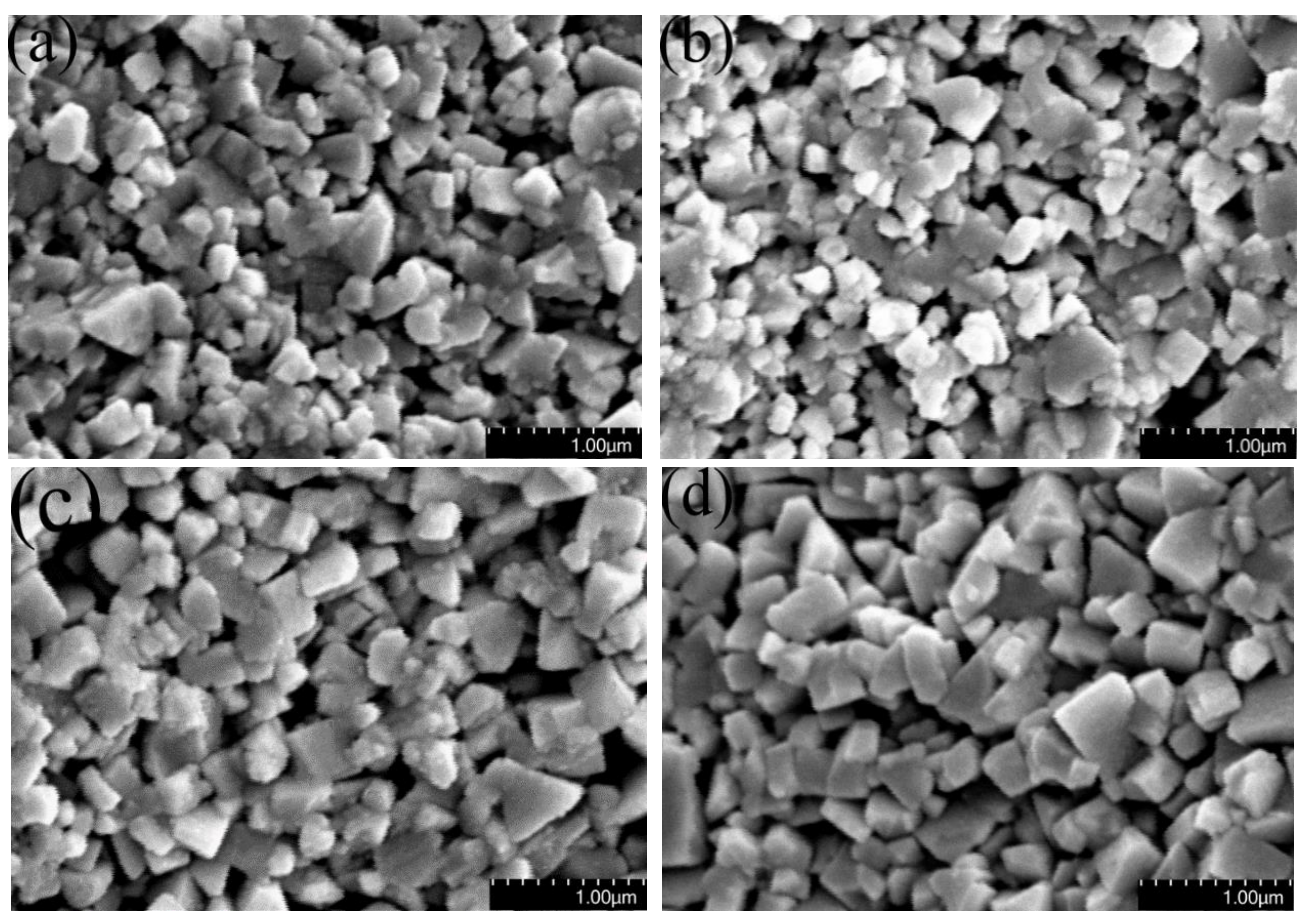

Figure 4. WC grain morphology of samples after holding for $1 \mathrm{~min}$ at (a) $1200^{\circ} \mathrm{C},(\mathbf{b}) 1250^{\circ} \mathrm{C},(\mathbf{c}) 1300^{\circ} \mathrm{C}$ and (d) $1350{ }^{\circ} \mathrm{C}$. 


\subsection{Analysis of Relative Density and Microstructure of Two-Step Sintered UYG12V}

Figure 5 shows the relationship between the relative density and holding time. Figure 5 shows that the relative density of the samples increases as the holding time increases. In the case where $t_{1}=2 \mathrm{~min}$ and $3 \mathrm{~min}$, the relative density of the samples reaches $99.4 \%$ when $\mathrm{t}_{2}=5 \mathrm{~min}$. In addition, in the case of $t_{1}=1 \mathrm{~min}$, the relative density of the samples reaches $98.9 \%$ when $t_{2}=7 \mathrm{~min}$. Thus, one can conclude that $t_{2}$ influences the relative density of the sintered sample. As the extension of $t_{2}$, the liquid phase exists for a longer time when $t_{2}$ is larger, which encourages the rearrangement of WC particles and increases the relative density of the samples.

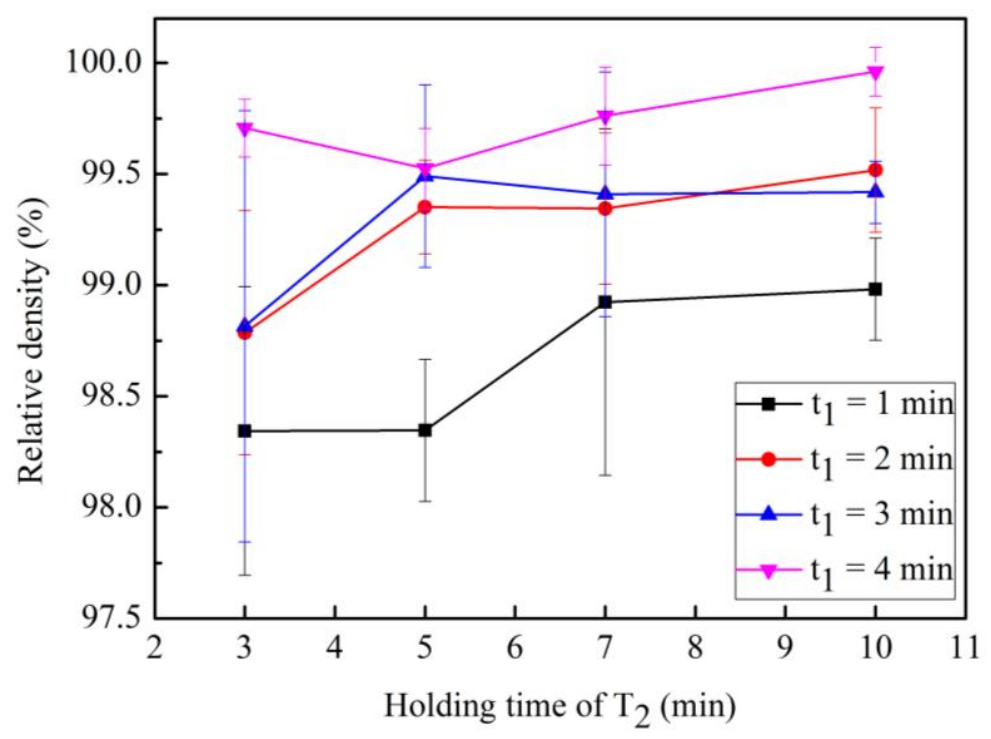

Figure 5. Relationship between sample relative density and holding time.

Figure 6 shows the fracture morphology of the sintered UYG12V cemented carbide. When the grain morphology of samples $1 \mathrm{a}$ and $1 \mathrm{~d}$ are compared, one finds that the irregular grain morphology of WC does not change as $t_{2}$ increases. On the contrary, when the grain morphology of samples $1 \mathrm{a}$ and $4 \mathrm{a}$ are compared, one finds that the grain morphology of WC tends to be more regular as $t_{1}$ increases, which favors grain rearrangement increases the relative density. Therefore, when $t_{1}=1 \mathrm{~min}$, the relative density tends to be low regardless of the value of $t_{2}$. A short holding time at high temperature causes the dissolution-precipitation of WC to occur at a high rate for a short period of time. Dissolution-precipitation will dissolve particles with a large surface curvature, and dissolved substances will precipitate in areas with negative curvature. The shapes of the resulting particles will be more flat, which is more conducive to the rearrangement of particles. Therefore, under the condition that the dissolution-precipitation of WC is suppressed, WC grains have some region with negative curvature and high relative density cannot be achieved only by prolonging the particle rearrangement time. The porosity of sample 1a can be seen in Figure 6a, and the irregular grain morphology of sample $1 \mathrm{a}$ can be seen in Figure $6 \mathrm{~b}$. One can conclude that $t_{1}$ in determining the morphology, which greatly affects the relative density of the sintered samples. Among all samples, the samples with $\mathrm{t}_{1}=4 \mathrm{~min}$ have the highest relative density, and changing $t_{2}$ has little effect on the relative density.

Figure 7 shows the relationship between the grain size and holding time, which indicates that the WC grain size increases as the holding time increases. This is inconsistent with the conclusion regarding the relationship between the grain size and holding time provided by Bao et al. [25], who pointed out that the effect of the holding time on the grain size is extremely small, and the grain size does not increase as the holding time increases. This difference may arise because Bao et al. reached this conclusion based on results from microwave sintering, wherein the heating rate is slow and the sintering time is long, in contrast to SPS. There may be a threshold holding time beyond which the grain growth rate becomes very slow. The holding time easily reaches this point during microwave 
sintering due to the long sintering time. However, unlike microwave sintering, SPS has a fast heating rate and short holding time. Therefore, the grain size is strongly affected by the holding time and grain growth can be controlled by adjusting the holding time in SPS. Smaller grains can be obtained by the two-step SPS than microwave sintering.

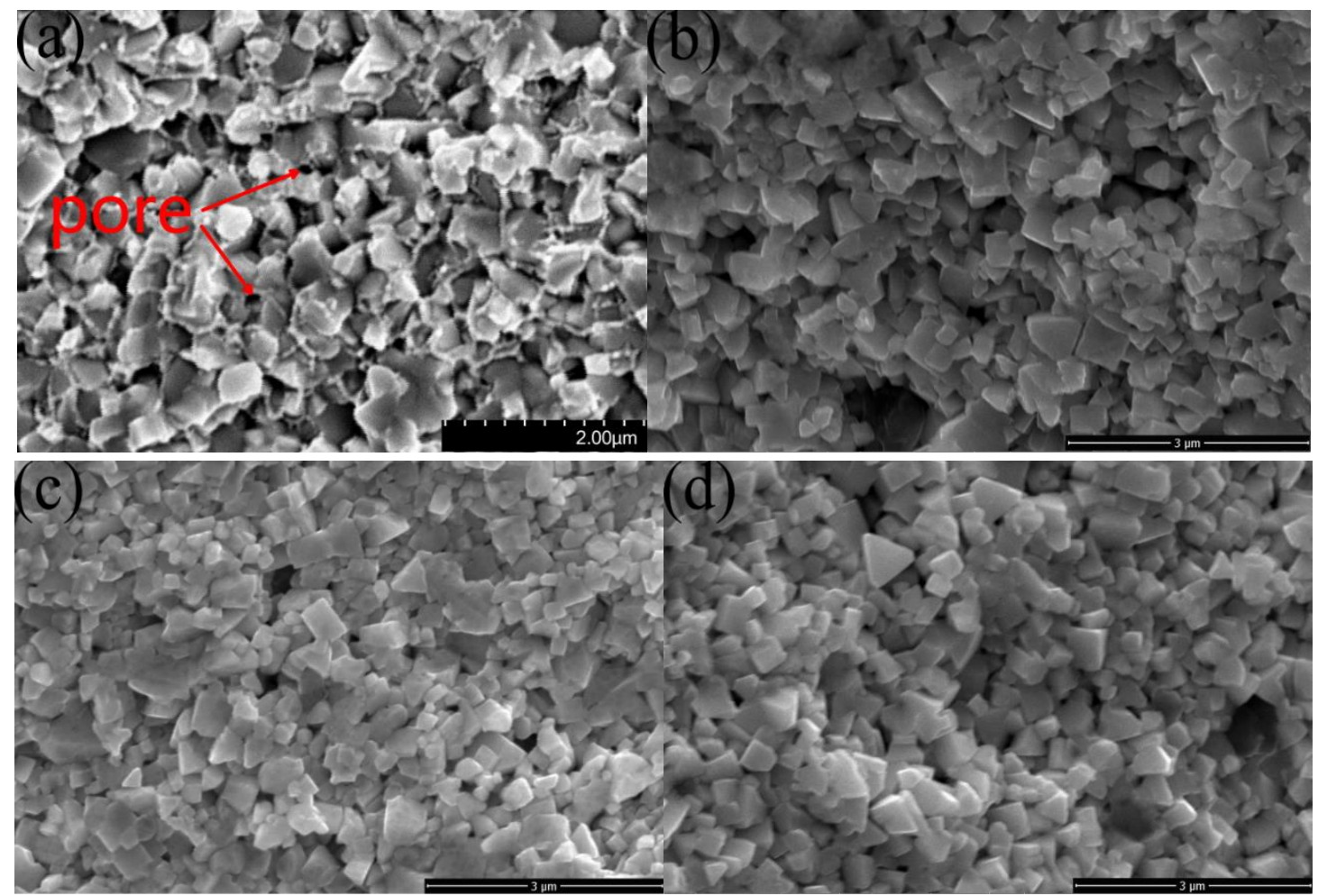

Figure 6. Fracture morphology of (a) 1a, (b) 1a (no Co), (c) 1d (no Co), (d) 4a (no Co) sample.

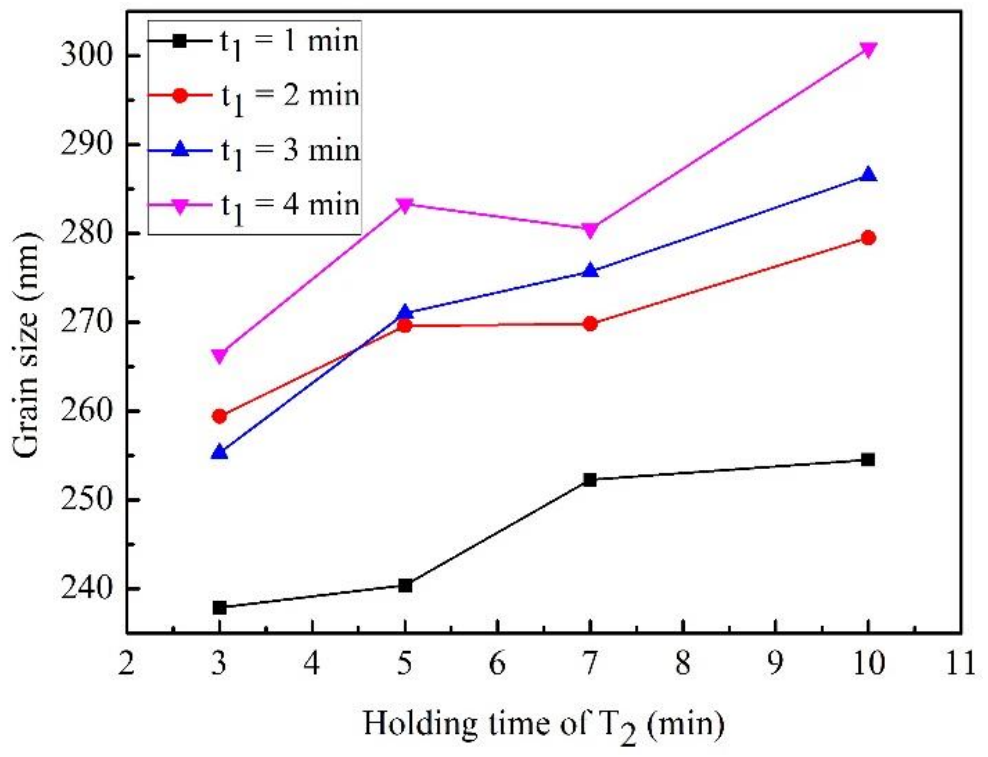

Figure 7. Relationship between the WC grain size and holding time.

In the two-step SPS process, the average growth rate of $\mathrm{WC}$ grains is $12.16 \mathrm{~nm} \mathrm{~min} \mathrm{~m}^{-1}$ at $\mathrm{T}_{1}$ and $3.67 \mathrm{~nm} \mathrm{~min} \mathrm{mi}^{-1}$ at $\mathrm{T}_{2}$. One can see that the effect of the holding time on the WC grain size at high temperature is greater than that at low temperature. 
Figure 8 shows the effect of the holding time on the WC grain distribution. One can see that the proportion of WC particles with the grain size larger than $500 \mathrm{~nm}$ increases as $t_{1}$ or $t_{2}$ increase. This is related to the overall grain growth, which increases the proportion of the large WC during a longer holding time. In general, during the two-step plasma sintering, increasing the holding time has little effect on the grain size distribution and does not cause a sudden increase in the number of abnormal grains.
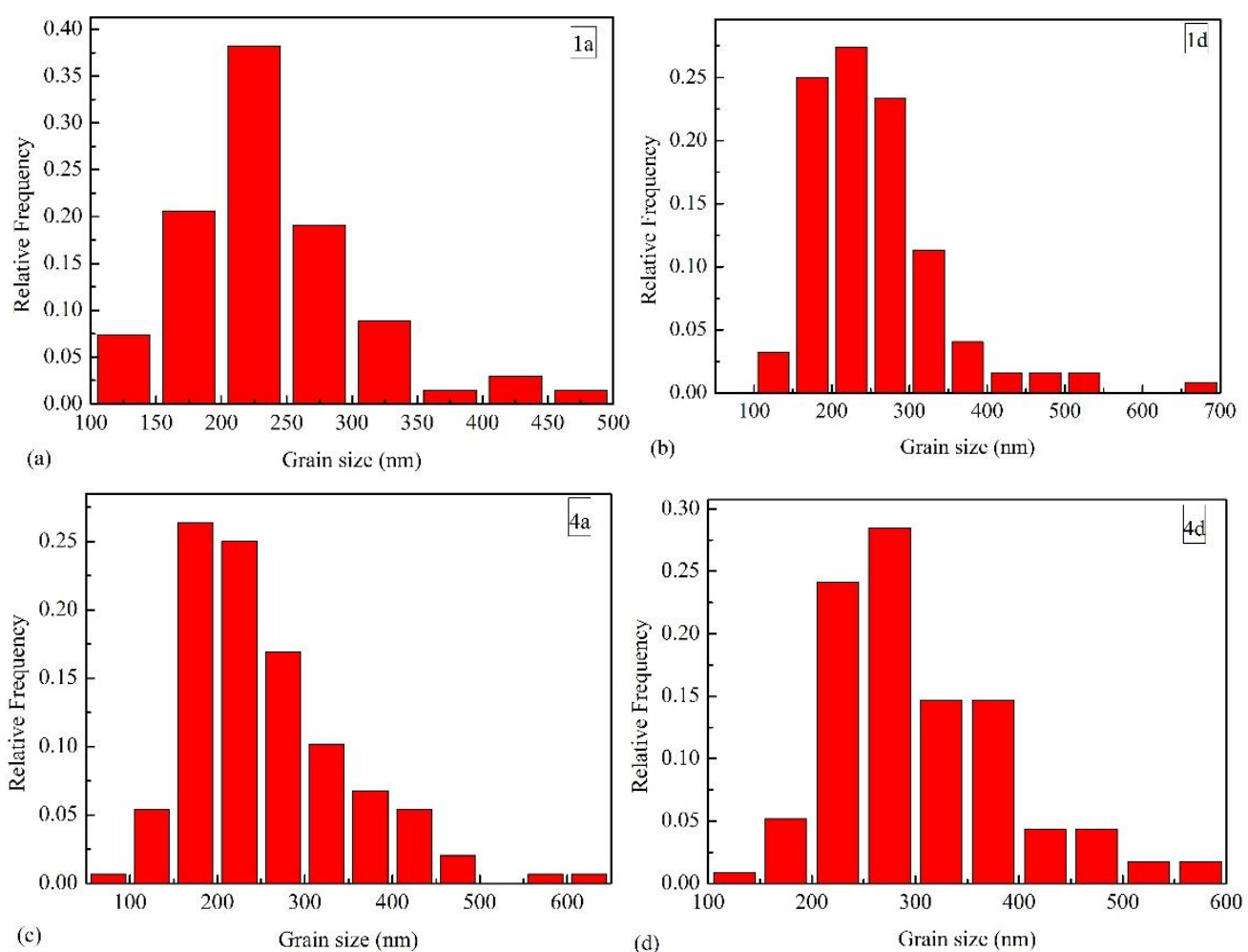

Figure 8. Grain size distribution of (a) 1a, (b) 1d, (c) 4a and (d) 4d sample.

\subsection{Analysis of Mechanical Properties during Two-Step Sintering of UYG12V}

The hardness of WC-Co cemented carbides tends to increase and then decrease as the sintering temperature or holding time increase. Moreover, the effect of the sintering temperature on the hardness of tungsten-cobalt cemented carbides is greater than the effect of the holding time. Therefore, using a low sintering temperature and short holding time will result in a material with low relative density and many pores, which decreases its hardness. In contrast, the high sintering temperature and long holding time will lead to the abnormal grain growth in WC-Co cemented carbides, which also decreases their hardness. Figure 9 shows the relationship between the selected mechanical properties and holding time. Figure 9a shows that the hardness of samples with high relative density increases first and then decreases as $t_{2}$ increases when $t_{1}=2$ or $3 \mathrm{~min}$. In the case where $t_{1}=1 \mathrm{~min}$, the hardness of samples is generally low due to their low relative density. However, in the case where $t_{1}=4 \mathrm{~min}$, the grain size of the samples increases, and increasing $t_{2}$ does not significantly affect their hardness values.

Figure $9 \mathrm{~b}$ shows the relationship between the fracture toughness and holding time. Compared with samples where $t_{1}=1$ or $4 \mathrm{~min}$, one can conclude that the fracture toughness of the samples decreases as the relative density increases. Crack propagation in the ultrafine grained cemented carbide occurs via the intergranular fracture rather than the transgranular fracture, and pores in the cobalt phase (Figure 6a) hinder crack propagation, which helps increase the fracture toughness of the samples [11]. When $t_{1}>1$ min for samples with higher relative density, harder samples have lower toughness, which may be related to the size of ultrafine WC particles and the distribution of cobalt. As the WC grain size is smaller, the thickness of the Co layer between the WC particles is smaller. Therefore, in 
ultrafine grained cemented carbides, the thickness of the Co layer tends to be lower than the critical value corresponding to the brittle Co [26].
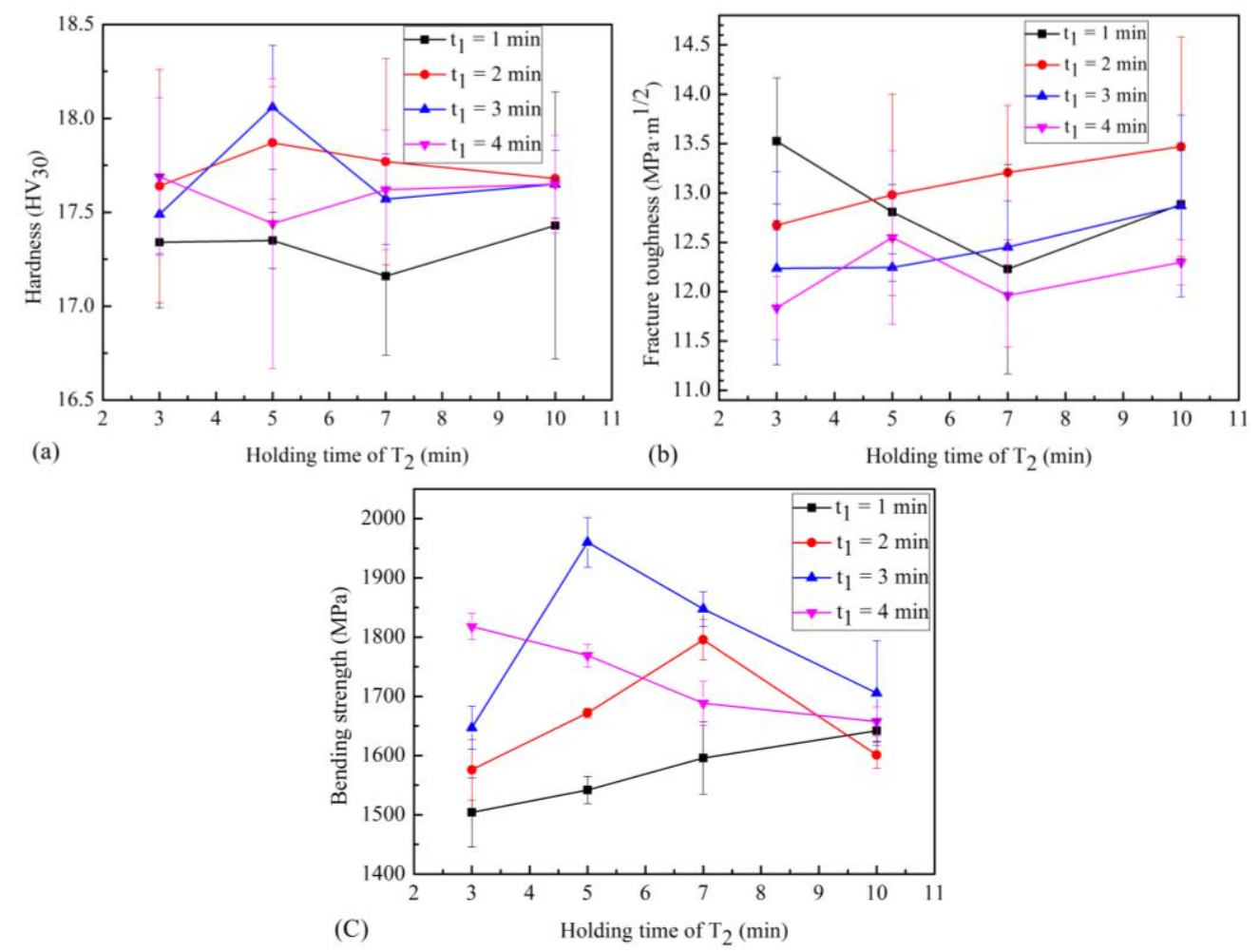

Figure 9. Relationship between the holding time and (a) hardness, (b) fracture toughness, and (c) bending strength.

Among the sixteen samples in our experiments, the hardness of sample $3 \mathrm{~b}$ was found to be the highest $(18.06 \mathrm{GPa})$, and the fracture toughness is $12.25 \mathrm{MPa} \mathrm{m}^{1 / 2}$. The fracture toughness of sample $1 \mathrm{a}$ is the highest $\left(13.53 \mathrm{MPa} \mathrm{m}^{1 / 2}\right)$, and its hardness is $17.34 \mathrm{GPa}$.

As shown in Figure 9c, the bending strength of the sintered samples increases and then decreases as $t_{2}$ increases when $t_{1}=2$ or $3 \mathrm{~min}$. Meanwhile, the bending strength of the samples decreases as $t_{2}$ increases when $t_{1}=4 \mathrm{~min}$. Finally, the bending strength of the samples increases as $t_{2}$ increases when $t_{1}=1 \mathrm{~min}$. Such changes are closely related to the low relative density of the samples caused by the short holding time and grain growth caused by the long holding time. Pores or grown grains maybe concentrate stress and become the starting points of crack propagation or fracture, thus decreasing the bending strength.

In summary, during the two-step sintering process, sample $3 \mathrm{~b}$ exhibits the highest hardness and bending strength with no obvious porosity and relatively uniform WC grain size (Figure 10). The average WC grain size of the ultrafine grained cemented carbides decreased from $362 \mathrm{~nm}$ to $271 \mathrm{~nm}$, and the relative density increased from $98.6 \%$ to $99.5 \%$, while the hardness increased from 17.79 GPa to18.06 GPa and the bending strength increased from $1899 \mathrm{MPa}$ to $1960 \mathrm{MPa}$, compared with the ultrafine grained cemented carbides prepared by Liu et al. using one-step sintering [27]. 


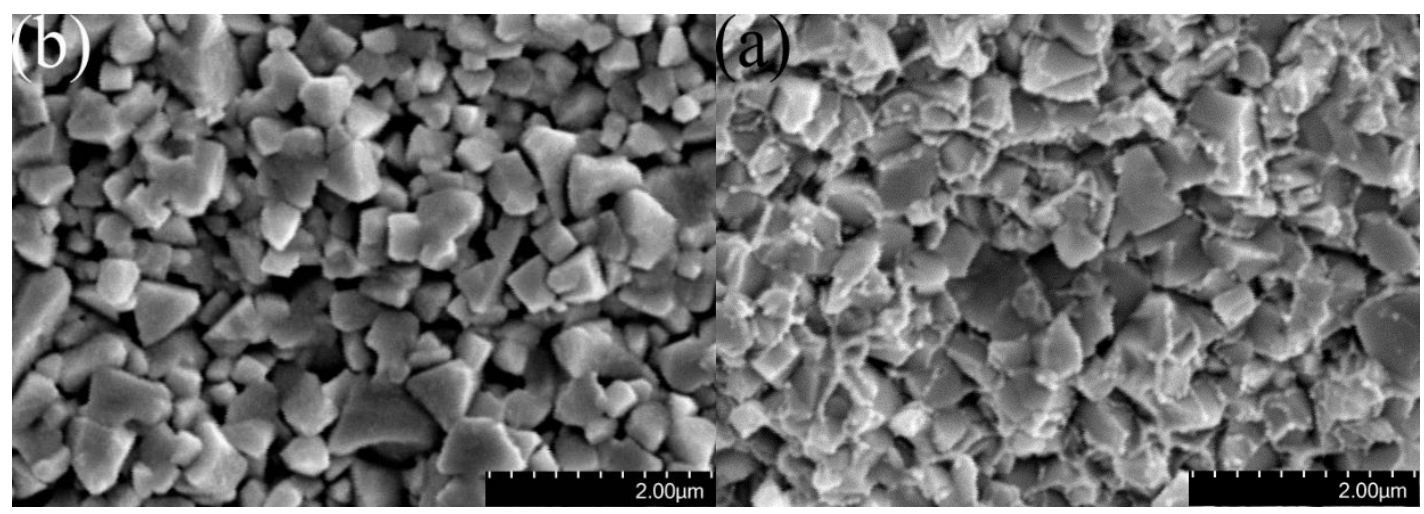

Figure 10. SEM image showing (a) containing Co and (b) no Co fracture morphology of $3 b$.

\section{Conclusions}

In this paper, UYG12V cemented carbides were prepared using the two-step SPS, and their relative densities, grain sizes, and mechanical properties were studied. During sintering, the liquid phase appears and the relative density of the sample increases rapidly at sintering temperatures ranging from between $1150{ }^{\circ} \mathrm{C}$ to $1200{ }^{\circ} \mathrm{C}$, during which the WC grains grow slowly. Increasing $\mathrm{t}_{1}$ or $\mathrm{t}_{2}$ increases the relative density, particularly $t_{1}$. The WC grain size of the cemented carbide is related to the holding time and sintering temperature, and the grain size increases as the holding time or sintering temperature increases. In addition, $t_{1}$ is a stronger determinant of the grain size than $t_{2}$ and plays a decisive role in determining the WC grain shape. UYG12V sintered at $1300{ }^{\circ} \mathrm{C}$ for $3 \mathrm{~min}$ and $1200{ }^{\circ} \mathrm{C}$ for 5 min exhibit an average particle size, Vickers hardness, fracture toughness, relative density, and bending strength of $271 \mathrm{~nm}, 18.06 \mathrm{GPa}, 12.25 \mathrm{MPa} \mathrm{m}^{1 / 2}, 99.49 \%$ and $1960 \mathrm{MPa}$, respectively.

Author Contributions: Conceptualization, Z.W.; Methodology, Z.W.; Validation, Z.W., B.W., Y.W., J.J.; Investigation, J.J.; Data curation, B.W. and Y.W.; Writing-original draft preparation, J.J. and Z.W.; resources, Z.W.; Writing-review and editing, Z.W. and J.J.; Supervision, Z.W.; Project administration, Z.W.; Funding acquisition, Z.W.

Funding: The work is supported by the National Key R\&D Program of China (Grant number 2018YFB2002200), National Natural Science Foundation of China (51775280), and the Jiangsu Provincial Six Talent Peaks Project (2016-HKHT-019).

Conflicts of Interest: The authors declare no conflict of interest.

\section{References}

1. Srivatsan, T.S.; Woods, R.; Petraroli, M.; Sudarshan, T.S. An investigation of the influence of powder particle size on microstructure and hardness of bulk samples of tungsten carbide. Powder Technol. 2002, 122, 54-60. [CrossRef]

2. Fang, Z.Z.; Wang, X.; Ryu, T.; Hwang, K.S.; Sohn, H.Y. Synthesis, sintering, and mechanical properties of nanocrystalline cemented tungsten carbide-A review. Int. J. Refract. Met. Hard Mater. 2009, 27, 288-299. [CrossRef]

3. Fayyaz, A.; Norhamidi, M.; Abu, B.S.; Javad, R.; Yee, N.W. Fabrication of cemented tungsten carbide components by micro-powder injection moulding. J. Mater. Process. Technol. 2014, 214, 1436-1444. [CrossRef]

4. Bonache, V.; Salvador, M.D.; Fernández, A.; Borrell, A. Fabrication of full relative density near-nanostructured cemented carbides by combination of VC/Cr3C2 addition and consolidation by SPS and HIP technologies. Int. J. Refract. Met. Hard Mater. 2011, 29, 202-208. [CrossRef]

5. Mannesson, K.; Borgh, I.; Borgenstam, A.; Agren, J. Abnormal grain growth in cemented carbides-experiments and simulations. Int. J. Refract. Met. Hard Mater. 2011, 29, 488-494. [CrossRef]

6. Mannesson, K.; Jeppsson, J.; Borgenstam, A.; Ågren, J. Carbide grain growth in cemented carbides. Acta Mater. 2011, 59, 1912-1923. [CrossRef]

7. Liu, X.; Song, X.; Wang, H.; Liu, X.; Tang, F.; Lu, H. Complexions in WC-Co cemented carbides. Acta Mater. 2018, 149, 164-178. [CrossRef] 
8. Morton, C.W.; Wills, D.J.; Stjernberg, K. The temperature ranges for maximum effectiveness of grain growth inhibitors in WC-Co alloys. Int. J. Refract. Met. Hard Mater. 2005, 23, 287-293. [CrossRef]

9. Song, X.; Gao, Y.; Liu, X.; Wei, C.; Wang, H.; Xu, W. Effect of interfacial characteristics on toughness of nanocrystalline cemented carbides. Acta Mater. 2013, 61, 2154-2162. [CrossRef]

10. Long, F.; Liu, X.Q.; Li, Y.; Ding, C.G.; Huo, J.; Li, L.X. Effect of Adding Different Inhibitors on Microstructure and Properties of Fine-grained WC-6Co Cemented Carbide. Powder Metall. Ind. 2013, 23, 16-21. (In Chinese)

11. Sivaprahasam, D.; Chandrasekar, S.B.; Sundaresan, R. Microstructure and mechanical properties of nanocrystalline WC-12Co consolidated by spark plasma sintering. Int. J. Refract. Met. Hard Mater. 2007, 25, 144-152. [CrossRef]

12. Thomas, R.; Churchill, C.A.; Sane, S.M. Microstructure and properties of ultrafine WC-0.6VC-10Co hardmetals densified by pressure-assisted critical liquid phase sintering. J. Alloy. Compd. 2004, 383, 98-102.

13. Zhu, H.; Ren, X.R.; Liu, M.X.; Xu, C. Effect of $\mathrm{Cu}$ on the microstructures and properties of WC-6Co cemented carbides fabricated by SPS. Int. J. Refract. Met. Hard Mater. 2017, 62, 155-160.

14. Guo, S.D.; Bao, R.; Yi, J.H.; Yang, J.G.; Liu, L.; Yang, P. Properties of molybdenum-containing WC-6Co cemented carbide prepared by SPS. J. China Nonferrous Met. 2018, 28, 556-564. (In Chinese)

15. Liu, S.C.; Wu, P.; Tong, S.; You, T.H.; Zeng, G.B. Study on Spark Plasma Sintering of Nano-WC-6\%Co Composite Powder. Cem. Carbide 2017, 349, 413-418. (In Chinese)

16. Wen, Y.; Zhang, Q.Y.; Guo, S.D.; Su, W.; Huang, Z.; Chen, H. SPS Sintering Process of WC-6Co Cemented Carbide. Nonferrous Met. Sci. Eng. 2017, 8, 74-78. (In Chinese)

17. Liu, Q.; Chen, J.; Yang, M.C. Effect of Vacuum Sintering Temperature and Holding Time on Microstructure and Properties of WC-6\%Ni fine-grained Cemented Carbide. Cem. Carbide 2017, 24, 393-397. (In Chinese)

18. Fabijanić, T.A.; Alar, Ž; Ćorić, D. Influence of consolidation process and sintering temperature on microstructure and mechanical properties of near nano- and nano-structured WC-Co cemented carbides. Int. J. Refract. Met. Hard Mater. 2016, 54, 82-89. [CrossRef]

19. Phuong, D.D.; Trinh, P.; Duong, L.; Chung, L.D. Influence of sintering temperature on microstructure and mechanical properties of WC-8Ni cemented carbide produced by vacuum sintering. Ceram. Int. 2016, 42, 14937-14943. [CrossRef]

20. Yang, Q.; Yang, J.; Yang, H.; Ruan, J. The effects of fine WC contents and temperature on the microstructure and mechanical properties of inhomogeneous WC-(fine WC-Co) cemented carbides. Ceram. Int. 2016, 42, 18100-18107. [CrossRef]

21. Xu, D.L.; Fang, C.C.; Zhan, Y.X.; Wang, H.Y.; Liang, Z.Y.; Wu, X.; Lin, Z. Microwave two-step sintering of alumina ceramics and its effect on toughness. J. Ceram. 2018, 39, 174-180. (In Chinese)

22. Yin, Z.; Yuan, J.; Xu, W.; Ye, J.; Liu, K.; Yan, S. Improvement in microstructure and mechanical properties of $\mathrm{Ti}(\mathrm{C}, \mathrm{N})$ cermet prepared by two-step spark plasma sintering. Ceram. Int. 2019, 45, 752-758. [CrossRef]

23. Zheng, D.; Li, X.; Li, Y.; Qu, S.; Yang, C. In-situ elongated $\beta$-Si3N4 grains toughened WC composites prepared by one/two-step spark plasma sintering. Mat. Sci. Eng. A-Struct. 2013, 561, 445-451. [CrossRef]

24. Long, J.Z. Effect of Sintering Temperature and Time on WC Grain Morphology of WC-24\%Co Cemented Carbide. Cem. Carbide 2017, 6, 370-377. (In Chinese)

25. Bao, R.; Yi, J.; Peng, Y.; Zhang, H. Effects of microwave sintering temperature and soaking time on microstructure of WC-8Co. Trans. Nonferrous Met. Soc. China 2013, 23, 372-376. [CrossRef]

26. Kim, H.C.; Shon, I.J.; Munir, Z.A. Rapid sintering of ultra-fine WC-10 wt $\%$ Co by high-frequency induction heating. J. Mater. Sci. 2005, 40, 2849-2854. [CrossRef]

27. Liu, K.; Wang, Z.; Yin, Z.; Cao, L.; Yuan, J. Effect of Co content on microstructure and mechanical properties of ultrafine grained WC-Co cemented carbide sintered by spark plasma sintering. Ceram. Int. 2018, 44, 18711-18718. [CrossRef]

(C) 2019 by the authors. Licensee MDPI, Basel, Switzerland. This article is an open access article distributed under the terms and conditions of the Creative Commons Attribution (CC BY) license (http://creativecommons.org/licenses/by/4.0/). 